\title{
EphB4 gene polymorphism and protein expression in non-small-cell lung cancer
}

\author{
MING-FENG ZHENG, YONG JI, XIAO-BO WU, SHU-GAO YE and JING-YU CHEN \\ Department of Cardiothoracic Surgery, The Affiliated Wuxi People's Hospital of \\ Nanjing Medical University, Wuxi, Jiangsu 214023, P.R. China
}

Received February 1, 2012; Accepted May 14, 2012

DOI: $10.3892 / \mathrm{mmr} .2012 .936$

\begin{abstract}
The objective of this study was to identify new diagnostic, prognostic or therapeutic molecules for non-smallcell lung cancer (NSCLC). We investigated the expression of EphB4, a tyrosine kinase receptor which has been shown to act as a tumor promoter in other cancers. Using immunohistochemistry, we visualized EphB4 expression in 28 samples of NSCLC and 12 samples of adjacent normal tissues. Additionally, we assessed a single-nucleotide polymorphism in EphB4 to determine its effect on protein expression. The correlation of both genotype and protein expression with disease severity was determined. EphB4 was expressed in $53.6 \%$ of patients with lung cancer, a significant increase compared to control lung samples $(0.0 \%, \mathrm{P}<0.05)$. Furthermore, EphB4 expression was correlated with differentiation, lymph node metastasis and TNM stage of tumors $(\mathrm{P}<0.05)$. Additionally, the polymorphism in EphB4 at rs314310 appeared to correspond to protein expression and disease susceptibility. While the frequencies of $\mathrm{CC}$, $\mathrm{CA}$ and AA genotypes were not different between lung cancer patients and healthy controls, the frequencies of $\mathrm{C}$ and $\mathrm{A}$ alleles were significantly different between these groups $(\mathrm{P}<0.05)$. Further analysis showed that the positive rate of EphB4 expression in patients with the AA genotype was significantly higher compared to that in patients with other genotypes $(\mathrm{P}<0.05)$. Overexpression of EphB4 plays a role in the occurrence and development of NSCLC, and the polymorphism at rs314310 may predispose individuals to this disease.
\end{abstract}

\section{Introduction}

Lung cancer, a primary malignant tumor of the lung, consists of two types, non-small-cell lung cancer (NSCLC) and smallcell lung cancer; NSCLC accounts for $80-85 \%$ of cases (1)

Correspondence to: Dr Yong Ji, Department of Cardiothoracic Surgery, The Affiliated Wuxi People's Hospital of Nanjing Medical University, Qingyang Road 299, Wuxi, Jiangsu 214023, P.R. China E-mail: jiyongmyp@126.com

Key words: non-small-cell lung cancer, EphB4, immunohistochemistry, polymerase chain reaction-restriction fragment length polymorphism, single-nucleotide polymorphism and has three subtypes: squamous cell lung cancer (SCC), adenocarcinoma (AC) and large cell carcinoma (LCC). Lung cancer is common and quite deadly: more than one million new cases arise each year (2), and the disease has the highest mortality among malignant tumors in both male and female patients (3). In 2008 alone, an estimated 215,010 new cases occurred in the US, and 161,840 patients died from the disease. The mortality of lung cancer also ranks first among malignant tumors in China. Epidemiological evidence collected in China revealed that 41.8 men and 19.3 women out of every 10 million individuals died in 2005 from lung cancer (4).

In the past 10 years, progress has been made in early diagnosis, surgery, radiotherapy and chemotherapy, significantly improving the 5-year survival rate of patients with common tumors (such as breast and prostate cancer). However, no significant breakthrough has been achieved in NSCLC. Currently, the 5-year survival rate of patients with these tumors is less than $9 \%$ in developing countries (2), and is the highest in the US - but still less than 15\% (5). Thus, advances in knowledge are required to improve the outcomes of this deadly disease.

Recent research in many tumor types has focused on biological molecules for use as prognostic, diagnostic and therapeutic approaches. One molecule that has garnered attention is the ephrin (Eph) receptor family. Eph represents the largest subfamily in the tyrosine kinase receptor family. The Eph subfamily consists of 16 genes, including EphB4 (6). EphB4 contributes to arterio-venous differentiation during angiogenesis (7). The protein is highly expressed in many tumors and appears closely related to tumor development and vascularization. Inhibiting EphB4 expression in breast tumors significantly reduces tumor cell proliferation, induces apoptosis and inhibits tumor invasion and metastasis (8).

While EphB4 is being heavily explored as a target in breast carcinoma, little is known about the role, if any, of this receptor in lung cancer, particularly NSCLC. To gain an understanding of EphB4 in NSCLC, particularly its potential utility in diagnosis and treatment, we investigated the expression of EphB4 in 28 samples of NSCLC in comparison to normal adjacent tissues. Additionally, we performed polymerase chain reaction-restriction fragment length polymorphism (PCR-RFLP) studies of peripheral blood from patients with NSCLC to identify the presence of the rs314310 (C/A) EphB4 single-nucleotide polymorphism (SNP) for correlation with protein expression and NSCLC. 


\section{Materials and methods}

Sample collection. Lung tissue and peripheral blood samples were collected from 28 patients with NSCLC undergoing surgery at the Department of Cardiothoracic Surgery, The Affiliated Wuxi People's Hospital of Nanjing Medical University. Cases were diagnosed pathologically. Detailed clinical data were available for each case, and none of the patients received pre-operative chemotherapy, radiotherapy or immunotherapy. The study population included 17 males and 11 females, 37-77 years of age (mean 56.3 \pm 11.5 ). Cases were classified according to the WHO revised proposal for histological types of lung and pleural tumors (9) as follows: 12 cases were SCC, 11 cases were AC and 5 cases were LCC; 8 cases were of histological grade I, 13 cases were of grade II and 7 cases were of grade III; 18 cases had no lymph node metastasis, while 10 cases had lymph node metastasis. TNM staging was performed according to UICC 1997 criteria, as follows: 17 cases were in stage I+II and 11 cases were in stage III+IV. For controls, 12 samples of adjacent normal lung tissue were obtained and 30 peripheral blood samples were collected from healthy individuals.

Immunohistochemistry. Lung tissues were fixed in neutral formalin, dehydrated and embedded in paraffin by conventional methods. Samples were sectioned $(4 \mu \mathrm{m})$ and collected on glass slides. Sections were then dewaxed with dimethylbenzene, rehydrated through an alcohol gradient, rinsed with distilled water, soaked in PBS for 5 min and heated for antigen retrieval. Upon cooling, 3\% hydrogen peroxide solution was used to block endogenous peroxidase activity. Slides were sealed with non-specific serum, then placed in a wet box and incubated at room temperature for 10 min. Primary antibody against EphB4 (rabbit anti-human polyclonal; Santa Cruz Biotechnology, Santa Cruz, CA, USA) was added to the wet box prior to overnight incubation at $4^{\circ} \mathrm{C}$. Slides were washed with PBS three times before the addition of biotinylated secondary antibody (Zhongshan-Golden Bridge Biotechnology Co., Ltd.) and incubated for $30 \mathrm{~min}$ at room temperature. Finally, slides were washed with PBS three times prior to addition of streptococcus avidin-peroxidase (SP kit; Fuzhou Maixin Biotechnology Development Co., Ltd.) and incubated at $37^{\circ} \mathrm{C}$ for $30 \mathrm{~min}$. DAB (Fuzhou Maixin Biotechnology Development Co., Ltd.) was used to develop staining. Sections were counterstained with haematoxylin, dehydrated through an ethanol gradient and sealed with neutral gum. Known positive tissues were used as a positive control, and PBS was used in place of the primary antibodies as a negative control.

EphB4 staining appeared as brownish-yellow granules in the cytoplasm (10). To assess staining intensity, 10 highpower fields were selected per sample. Scores were assigned as follows: no staining (uncolored) received a score of 0 , pale yellow staining received 1 , yellow staining received 2 and brownish-yellow staining received 3 . The proportion of tumor cells staining positively for EphB4 was determined and assigned a score as follows: $\leq 5 \%$ of tumor cells staining positively was scored as $0,6-25 \%$ positive was scored as 1 , $26-50 \%$ positive was scored as $2,51-75 \%$ positive was scored as 3 and $\geq 76 \%$ positive was scored as 4 . The sums of the scores of staining intensity and the proportion of positive cells generated the total scores for each sample. Totals are classified as follows: 0 as (-), 1-2 as (+), 3-5 as (++) and 6-7 as (+++).

PCR-RFLP method. DNA was extracted from peripheral blood according to methods by Lahiri and Schnabel (11). PCR amplification of EphB4 was performed with the following primers: forward, 5'-GAAGGACGGGGTGTTTG-3'; reverse, 5'-GTTGGCACTTAGCAGAAGA-3'. Reaction mix (25 $\mu 1$ total) contained $0.1 \mu \mathrm{g}$ template DNA, $0.25 \mathrm{mM}$ dNTP, 1 unit TaqDNA polymerase (Takara, Japan), $2.0 \mathrm{mM} \mathrm{MgCl} 2,1 \mathrm{X}$ PCR buffer and $2.0 \mathrm{mM}$ of each primer. Reaction conditions were as follows: denaturation at $95^{\circ} \mathrm{C}$ for $5 \mathrm{~min} ; 35$ cycles of denaturation at $94^{\circ} \mathrm{C}$ for $50 \mathrm{sec}$, annealing at $60^{\circ} \mathrm{C}$ for $1 \mathrm{~min}$ and extension at $74^{\circ} \mathrm{C}$ for $1 \mathrm{~min}$; and final extension at $72^{\circ} \mathrm{C}$ for $5 \mathrm{~min}$. For restriction digestion to identify the polymorphism at rs314310, a 15- $\mu 1$ amplified product was incubated with 5 units of restriction enzymes (MBI, USA) and the corresponding buffer in a water bath at $37^{\circ} \mathrm{C}$ for $16 \mathrm{~h}$. Fragments were separated on a $2 \%$ agarose gel.

Statistical analysis. SPSS17.0 statistical software was used for statistical analysis. The $\chi^{2}$ test was used to compare the expression of EphB4 protein and genotype and allele frequencies among groups. Tests were two-sided, with $\alpha=0.05 ; \mathrm{P}<0.05$ denoted statistical significance.

\section{Results}

Expression of EphB4 protein in NSCLC and adjacent normal lung samples. EphB4 expression was detected in lung tissues as expected. To determine differences in EphB4 expression between NSCLC and normal lung tissue, we assessed both the intensity of staining and proportion of positive cells within samples; scores were combined as described above and classified as '-' (low intensity and small proportion) to '+++' (high intensity and large proportion). EphB4 was expressed in 53.6\% $(15 / 28)$ of NSCLC samples, but in none of the 12 adjacent normal lung tissue samples (Table I). Expression of EphB4 in NSCLC was significantly more intense and more common than in normal lung tissue $\left(\chi^{2}=10.286, \mathrm{P}=0.016\right)$.

Correlation between EphB4 expression and clinicopathological parameters of NSCLC. To determine whether the increased expression of EphB4 protein in NSCLC tissues was correlated with disease progression, we compared staining degree with clinical and pathological parameters, including age and tumor severity. EphB4 was significantly associated with differentiation degree, lymph node metastasis and TNM staging (all $\mathrm{P}<0.05$ ), but not with gender, age or type of NSCLC (Table II).

Polymorphism in EphB4. PCR-RFLP was used to detect the (C/A) polymorphism at EphB4 rs314310 in blood samples from 28 NSCLC cases and 30 healthy individuals. PCR amplification was expected to produce three different possible fragment sizes (10), as follows: CC genotype would be visualized as a single band of $320 \mathrm{bp}$; AA genotype would be visualized as two fragments, 215 and $105 \mathrm{bp}$; and CA genotype would be visualized as three fragments, 105, 215 and $320 \mathrm{bp}$.

The distribution of CC, CA and AA genotypes between 28 cases of NSCLC and 30 controls was not significantly 
Table I. Expression of EphB4 in non-small-cell lung cancer (NSCLC) and adjacent normal lung tissues [n (\%)].

\begin{tabular}{lccccc}
\hline Sample tissue & no. & - & + & ++ & +++ \\
\hline NSCLC & 28 & $13(46.4)$ & $6(21.4)$ & $5(17.9)$ & 0 \\
Adjacent normal lung & 12 & $12(100.0)$ & 0 & 0 & 0 \\
Total & 40 & $25(14.3)$ & $5(12.5)$ & $4(10.0)$ \\
\hline
\end{tabular}

$\chi^{2}=10.286, \mathrm{P}=0.016$.

Table II. Correlation between EphB4 expression and clinicopathological parameters in non-small cell lung cancer [n (\%)].

\begin{tabular}{|c|c|c|c|c|c|c|c|}
\hline Parameters & no. & - & + & ++ & +++ & $\chi^{2}$ test & $\mathrm{P}$-value \\
\hline Gender & & & & & & 5.188 & 0.159 \\
\hline Male & 17 & $10(58.8)$ & $4(23.5)$ & $1(5.9)$ & $2(11.8)$ & & \\
\hline Female & 11 & $3(27.3)$ & $2(18.2)$ & $4(36.4)$ & $2(18.2)$ & & \\
\hline Age (years) & & & & & & 2.029 & 0.566 \\
\hline$<60$ & 16 & $8(50.0)$ & $2(12.5)$ & $3(18.8)$ & $3(18.8)$ & & \\
\hline$\geq 60$ & 12 & $5(41.7)$ & $4(33.3)$ & $2(16.7)$ & $1 \quad(8.3)$ & & \\
\hline Histology & & & & & & 6.192 & 0.402 \\
\hline Squamous cell carcinoma & 12 & $5(41.7)$ & $4(33.3)$ & $2(16.7)$ & $1(8.3)$ & & \\
\hline Adenocarcinoma & 11 & $6(54.5)$ & 0 & $3(27.3)$ & $2(18.2)$ & & \\
\hline Large cell carcinoma & 5 & $2(40.0)$ & $2(40.0)$ & 0 & $1(20.0)$ & & \\
\hline Differentiation & & & & & & 13.620 & 0.034 \\
\hline I & 8 & $7(87.5)$ & 0 & 0 & $1(12.5)$ & & \\
\hline II & 13 & $5(38.5)$ & $5(38.5)$ & $2(15.4)$ & $1 \quad(7.7)$ & & \\
\hline III & 7 & $1(14.3)$ & $1(14.3)$ & $3(42.9)$ & $2(28.6)$ & & \\
\hline Lymph node metastasis & & & & & & 12.644 & 0.005 \\
\hline No & 18 & $11(61.1)$ & $5(27.8)$ & 0 & $2(11.1)$ & & \\
\hline Yes & 10 & $2(20.0)$ & $1(10.0)$ & $5(50.0)$ & $2(20.0)$ & & \\
\hline TNM stage & & & & & & 8.817 & 0.032 \\
\hline $\mathrm{I}+\mathrm{II}$ & 17 & $11(64.7)$ & $4(23.5)$ & $1 \quad(5.9)$ & $1 \quad(5.9)$ & & \\
\hline III+IV & 11 & $2(18.2)$ & $2(18.2)$ & $4(36.4)$ & $3(27.3)$ & & \\
\hline
\end{tabular}

Table III. Genotype and allele frequencies of EphB4 rs314310 (C/A) [n (\%)].

\begin{tabular}{|c|c|c|c|c|c|c|}
\hline \multirow[t]{2}{*}{ Group } & \multirow[t]{2}{*}{ no. } & \multicolumn{3}{|c|}{ Genotype frequency ${ }^{a}$} & \multicolumn{2}{|c|}{ Allele frequency ${ }^{\mathrm{b}}$} \\
\hline & & $\mathrm{CC}$ & $\mathrm{CA}$ & AA & $\mathrm{C}$ & A \\
\hline NSCLC patients & 28 & $7(25.0)$ & $15(53.6)$ & $6(21.4)$ & $29(51.8)$ & $27(48.2)$ \\
\hline Healthy individuals & 30 & $13(43.3)$ & $16(53.3)$ & $1 \quad(3.3)$ & $42(70.0)$ & $18(30.0)$ \\
\hline Total & 58 & $20(34.5)$ & $21(53.4)$ & $7(12.1)$ & $71(61.2)$ & $45(38.8)$ \\
\hline
\end{tabular}

${ }^{\mathrm{a}} \chi^{2}=5.341, \mathrm{P}=0.069 ;{ }^{\mathrm{b}} \chi^{2}=4.047, \mathrm{P}=0.044$. NSCLC, non-small cell lung cancer.

different; however, the difference in allele frequencies of $\mathrm{C}$ and $\mathrm{A}$ alleles was significantly different between the NSCLC and control populations $\left(\chi^{2}=4.047, \mathrm{P}=0.044\right.$; Table III).

Correlation between expression of EphB4 and genotype in NSCLC. To determine whether differences in the EphB4 genotype corresponded to EphB4 expression, we compared all NSCLC patients with the AA genotype. The expression rates for $\mathrm{CC}, \mathrm{CA}$ and $\mathrm{AA}$ genotypes were 0, 60 and 100\%, respectively. This difference in the expression of EphB4 in NSCLC patients by genotype was significant $\left(\chi^{2}=18.862\right.$, $\mathrm{P}=0.004)$. 
Table IV. Correlation between $E p h B 4$ genotype and protein expression in non-small-cell lung cancer [n (\%)].

\begin{tabular}{|c|c|c|c|c|c|c|}
\hline Genotype & no. & & - & + & ++ & +++ \\
\hline $\mathrm{CC}$ & 7 & & (100.0) & 0 & 0 & 0 \\
\hline $\mathrm{CA}$ & 15 & 6 & $(40.0)$ & $5(33.3)$ & $3(20.0)$ & $1(6.7)$ \\
\hline AA & 6 & & 0 & $1(16.7)$ & $2(33.3)$ & $3(50.0)$ \\
\hline Total & 28 & 13 & (46.4) & $6(21.4)$ & $5(17.9)$ & $4(14.3)$ \\
\hline
\end{tabular}

$\chi^{2}=18.862, P=0.004$.

\section{Discussion}

Members of the Eph family of tyrosine kinase receptors are widely distributed, highly conserved and play important roles in embryogenesis, neural targeting, angiogenesis and formation (12). EphB4 is characterized by three domains, the extracellular ligand-binding domain, the intracellular functional domain with tyrosine kinase activity and the transmembrane domain (13). After activation, EphB4 migrates to and aggregates on the cell membrane and forms oligomeric complexes. This leads to autophosphorylation and tyrosine phosphorylation of a large number of reverse intracellular substrate proteins and initiates bidirectional signal regulation. These activities of EphB4 make it important in cell growth, proliferation, differentiation and chromosome division, as well as in embryogenesis, neural network formation, directed neuronal migration, axon route guiding and other important physiological processes (14).

Additionally, EphB4 functions in tumor angiogenesis and is therefore of interest as a tumor promoter (15). Expression of this protein is increased in many types of tumor tissues and cell lines, although not observed in corresponding normal tissues. Stephenson et al (16) used quantitative RT-PCR to detect expression in colon cancer tissue from 62 patients and found that EphB4 expression increased in $82 \%$ of tumor samples. Furthermore, analyzing tissue samples by immunohistochemistry and western blotting, they found EphB4 receptor expression in epithelial cells of tumor tissues, but no or low EphB4 receptor expression in normal tissues. Similarly, we found that EphB4 protein expression in NSCLC tissues was significantly higher compared to adjacent normal lung tissues. In addition, EphB4 expression was correlated with the severity of NSCLC, consistent with findings in endometrial cancer reported by Takai et al (17). Thus, EphB4 expression appears closely related to the malignancy and progression of NSCLC.

SNP analysis has become a common approach to identifying alleles that may contribute to disease susceptibility or severity (18). Polymorphisms affect gene expression levels or produce altered gene products that, in turn, affect protein expression to result in disease. A polymorphism in EphB4 was identified in the dbSNP database as rs314310 (10). We determined that the $\mathrm{C} / \mathrm{A}$ nucleotide variation in this gene correlated with altered expression of EphB4 in NSCLC. While we found no statistically significant difference in $\mathrm{CC}, \mathrm{CA}$ and AA genotype frequencies between NSCLC patients and healthy individuals, a statistically significant difference in $\mathrm{C}$ and A allele frequencies was observed. Furthermore, EphB4 was expressed in all patients with the AA genotype, but in none of the patients with the CC genotype. Thus, the EphB4 polymorphism affects protein expression, which is, in turn, is related to NSCLC susceptibility. While promising, these results require validation in other populations with a larger sample size.

In summary, EphB4 protein expression is significantly increased in NSCLC and corresponds to progression and severity of the disease. Additionally, EphB4 polymorphism affects protein expression, and the $\mathrm{A}$ allele appears related to NSCLC susceptibility. Thus, EphB4 genotyping may be a valuable indicator of disease susceptibility, while EphB4 expression may be useful as a prognostic marker for NSCLC.

\section{References}

1. Parkin DM, Bray F, Ferlay J and Pisani P: Global cancer statistics, 2002. CA Cancer J Clin 55: 74-108, 2005.

2. Jemal A, Siegel R, Ward E, Murray T, Xu J and Thun MJ: Cancer statistics, 2007. CA Cancer J Clin 57: 43-66, 2007.

3. Yang L, Parkin DM, Li LD, Chen YD and Bray F: Estimation and projection of the national profile of cancer mortality in China: 1991-2005. Br J Cancer 90: 2157-2166, 2004.

4. Murray T, Siegel R, Ward E, et al: Cancer statistics, 2008. CA Cancer J Clin 58: 71-96, 2008.

5. Jemal A, Siegel R, Ward E, et al: Cancer statistics, 2006. CA Cancer J Clin 56: 106-130, 2006.

6. Pasquale EB: Eph receptor signalling casts a wide net on cell behaviour. Nat Rev Mol Cell Biol 6: 462-475, 2005.

7. Erber R, Eichelsbacher U, Powajbo V, et al: EphB4 controls blood vascular morphogenesis during postnatal angiogenesis. EMBO J 25: 628-641, 2006.

8. Kumar SR, Singh J, Xia G, et al: Receptor tyrosine kinase EphB4 is a survival factor in breast cancer. Am J Pathol 169: 279-293, 2006.

9. Shimosato Y: Histological typing of lung and pleural tumors (3rd edition, 1999): malignant epithelial tumors. Nihon Rinsho 60: 123-131, 2002.

10. Shen LQ, Wang XC, Zhao J, Di HZ and Zhuang ZX: Association between Eph4 gene polymorphism and non-small cell lung cancer. Chin J Clin Oncol 31: 778-779, 2009.

11. Lahiri DK and Schnabel B: DNA isolation by a rapid method from human blood samples: effects of $\mathrm{MgCl}_{2}$, EDTA, storage time, and temperature on DNA yield and quality. Biochem Genet 31: 321-328, 1993.

12. Yarden $Y$ and Ullrich A: Growth factor receptor tyrosine kinases. Annu Rev Biochem 57: 443-478, 1988.

13. Himanen JP and Nikolov DB: Eph signaling: a structural view. Trends Neurosci 26: 46-51, 2003.

14. Wang HU, Chen ZF and Anderson DJ: Molecular distinction and angiogenic interaction between embryonic arteries and veins revealed by ephrin-B2 and its receptor Eph-B4. Cell 93: 741-753, 1998.

15. Cheng N, Brantley DM and Chen J: The ephrins and Eph receptors in angiogenesis. Cytokine Growth Factor Rev 13: 75-85, 2002.

16. Stephenson SA, Slomka S, Douglas EL, Hewett PJ and Hardingham JE: Receptor protein tyrosine kinase EphB4 is up-regulated in colon cancer. BMC Mol Biol 2: 15-17, 2001.

17. Takai N, Miyazaki T, Fujisawa K, Nasu K and Miyakawa I: Expression of receptor tyrosine kinase EphB4 and its ligand ephrin-B2 is associated with malignant potential in endometrial cancer. Oncol Rep 8: 567-573, 2001.

18. Nowotny P, Kwon JM and Goate AM: SNP analysis to dissect human traits. Curr Opin Neurobiol 11: 637-641, 2001. 